\title{
Special Education and ICTs
}

\author{
http://dx.doi.org/10.3991/ijet.v8i2.2514 \\ Athanasios S. Drigas, and Rodi-Eleni Ioannidou \\ NCSR DEMOKRITOS, Athens, Greece
}

\begin{abstract}
Recent development in special education includes the use of Information and Communication Technologies (ICTs) to assist students during their lifetime. ICT is now also recognized as a tool which ensures access to knowledge and learning resources. In this paper we present an overview of the most representative studies of the last decade (2001-2010) which deal with the two important issues in the field of special education, diagnosis and intervention. One important advantage of these tools is that they can be employed by teachers and parents as well, to adapt education to the needs and abilities of pupils. The studies chosen will be classified according to the areas of needs they serve.
\end{abstract}

Index Terms-assessment, ICT, intervention, learning difficulties, special education

\section{INTRODUCTION}

Rapid developments in information technology have dramatically changed the living conditions for many people during the past decades. The term Information and Communication Technologies (ICTs) is a general term which refers to all kinds of technologies that enable users to access and manipulate information [1]. ICTs have been widely studied in a large number of fields as well as being a subject of study in its own right. One of the several fields that gathered accumulative evidence around it is the use of technology in education. The effect of ICT in education has been studied since the beginning of the 1970 s, where educators started to become increasingly convinced that ICTs could support students in formal education [2].

Recently, there has been an increasing emphasis on educating all children and ensuring the learning needs of all young people and adults. Education should create conditions needed to optimize learning and ensure the transfer of knowledge and skills. This fact has reinforced the use of technology as a mean of overcoming barriers to learning. There is now a general agreement amongst different specialists that Information and Communications Technology (ICT) can enhance a child's educational, social and cultural experiences. The successful integration of ICT into learning environments has the potential to benefit all students as well as students with special educational needs.

The term 'Special Educational Needs' refers to all types of difficulties that can cause problems during the learning process. However, there have been observed various terms amongst countries due to differences in culture, language, ethnicity [3]. Across all types of special educational needs there are also differences in the research methods used. There are models which emphasize needs within the person from a medical, educational or psychological perspective. Our scoping study drew upon national and international publications, research findings and decided to use the following categorization [4].

'The areas of needs' as defined in the 2001 SEN Code of Practice are:

- Communication Interaction

- Sensory and/or Physical, Cognition and Learning

- Behaviour

- Emotional and Social Development

(Department for Education and Skills 2001:\$7:52, p.85)

Special educational needs vary in the degree to which they affect a person's learning. They can be long-lasting or short term. There are individuals who quite frequently have more than one form of difficulties. It is then necessary to create environments where learners with varying diversities and abilities have the opportunity to meet and develop [5]. A growing field of research indicated the need to expand the use of ICT in school, home social and/or virtual community. Most of these studies clearly agree that the use of ICT can give people with disabilities equal opportunities in learning and facilitate daily life, maximize their independence and promote self-advocacy [6].

The integration of ICTs in special education deals with several issues such as assistive or enabling technology, internet applications, augmentative communication systems, adaptive devices [7]. This paper will focus on some of the most representative studies which introduce software applications programs for diagnosis and intervention purposes of specific difficulties. Most of the time these procedures are complicated, need a lot of effort, attention, patience and above all require persons wellqualified and with responsibility. During the last decade, much of the research on learning with ICTs deals with different types of diagnostic and intervention tools which can be used not only from specialists such as doctors, but also from teachers, special educators and parents. Recently, computer based assessment systems have been supported from a large number of researchers because they can better recognize and integrate learning difficulties across students [8], [9]. In addition great progress has been observed in the design of ICT software programs to provide students with special educational needs equal access to education [10], [11]. In order for these studies to be presented, we created a framework according to the above 'areas of needs' categorization, which consists of two main sections. The first one includes diagnostic and intervention tools regarding people with sensory and physical impairments (visually impaired learners, deaf and hearing impaired learners, learners with motor impairments) while the next one includes the major domains of learning difficulties. 


\section{SENSORY AND PHYSICAL IMPAIRMENTS}

\section{A. Visually Impaired Learners}

According to the World Health Organization [12], about 314 million individuals are visually impaired worldwide. Increasing numbers of individuals with a visual impairment are using technology to access information [13]. The research field about ICT assessment regarding visually impaired people is very limited due to the fact that vision tests are procedures conducted almost exclusively from doctors. In addition, it is difficult for a practitioner or an educator to implement assessment tests because of the lack of equipment and lack of training [14]. To help visually impaired students a large number of ICTs have been developed to facilitate learning process and their everyday life.

However, Fujiyoshi et al. (2010) introduced a testing system with a digital audio player and document structure diagrams for newly blind users who have difficulties in Braille or print. The system gives them the chance to take the National Center Test for university admission. This study showed that the audio tests results were almost similar to normal-print-format and braille-format tests in score [15].

Westin (2004) presented a real-time 3D graphic game 'Terraformers', accessible for blind and low vision users as well as full sighted gamers. It has considered a game easy to use focused on the sound interface and how it relates to the 3D graphic world [16].

Raisamo et al., (2006) introduced a multimodal computer system for preschool and primary school students in order to support children's conceptual learning. It's an elearning environment consisting of six micro words, each one representing an astronomical phenomenon, which the students can explore independently. There is no need for the presence of an adult since the child is guided by imaginary characters, called agents. The agents help the child explore the system by making suggestions and asking questions [17].

Choi and Walker (2010) developed the Digitizer Auditory Graph, a sonification software tool which allows users to take an image of a line graph with an optical input device (e.g. webcam) and then hear an auditory graph of the digitized graph image. This tool helps both teachers and students, since teachers have difficulties in explaining graphs and visually impaired students' access to graphs is limited. Experimental results suggest that the users are able to understand the auditory output while using the optical input helps them create graphs easier and faster [18].

\section{B. Deaf and Hearing Impaired Learners}

Hearing problems affect also an amount of the special educational needs population. Hearing loss symptoms often vary and sometimes occur gradually so the learners do not realize it is happening. Computer-based audiometry is a field with accumulative research around it [19], [20]. In addition, ICT intervention and support for students with hearing problems is of major significance because they have equal access to knowledge and learning resources.

KUDUwave 5000 (GeoAxon, Pretoria, South Africa) is a recent computer-based telemedicine-compliant audiometer tool designed for remote testing of individuals across continents. Apart from the software application, the system uses also circumaural earcups that are placed over the earphones for additional attenuation. This tool has been tested from North America on people in South Africa with promising results [21], [22].

Drigas et al., in 2005 presented a Learning System designed for deaf and hard of hearing people. This prototype system offers Greek Sign Language videos in correspondence to all texts in the learning environment. The students for the first time have the opportunity to learn in their own language, the Greek sign language. The system includes also the involvement of the teacher and the administrator. Through appropriate training the users evaluate the knowledge they gained and they continue in further study [23].

Miller et al. (2008) designed the Speech Perception Assessment and Training System (SPATS). SPATS application is designed to improve a person's perception of natural everyday speech. The SPATS system implicitly trains the users' attentional focus while teaches the phonetic structure of English and the relation between production and perception. The evaluations of SPATS training application report that it gives the option of constructing a programmed curriculum tailored to student's needs and then automatically guides training [24].

In 2008 Drigas et al., presented 'Dedalos' project which deals with the teaching of the English language as a second language to deaf people. In developing this system, the researchers created a platform which includes methods such as distant linguistic training and an educational e-content designed specifically for the needs of this group of people. The project promotes a complete support system for the education of the deaf and hearing impaired individuals while at the same time opens the way for the inclusion of the deal and hearing impaired Greek students in Greece [25].

\section{Learners with Motor Impairments}

Opportunities for students with physical disabilities to participate in school or home settings have been the focus of many studies of ICT use. For this group of learners in order to access utilities software, it is often necessary the use of assistive devices such as touch screens, trackerballs, joysticks, keyboards and mouse alternatives [7]. Students with motor disabilities have different capabilities and needs. ICT could play an essential role as an inclusion tool in the school [11]. In order for an ICT intervention tool to be effective it is always best to discuss before implementing any adaptations to practice.

Chen et al., (2006) created CAT system a computerized assessment tool which evaluates a student's pointing and selecting proficiency. This assessment module consists of three sub-assessment systems and each one has its own purpose and assessment items. They are designed to measure speed, accuracy and efficiency of each evaluation tasks. CAT system was developed and later it was modified for another study and the design of Mi-CAT tool. MiCAT provide the professionals involved with multiple indicators relevant to the child's pointing and selecting performance in order to decide whether a pointing device is proper for a student. This method has been tested on a seven year old girl diagnosed with quadriplegia cerebral palsy with promising results [26], [27].

In 2008 Chin et al., introduced an integrated electromyogram and eye-gaze tracking cursor control system for 
PAPER

\section{SPECIAL EDUCATION AND ICTS}

individuals with motor disabilities. This system was designed for users who are unable to use their hands due to spinal dysfunction or other afflictions. The basic components of the system are the electromyogram (EMG) signals from muscles in the face and point-of-gaze coordinates produced by an eye-gaze tracking system (EGT). Additionally EMG-EGT system enables users to modify cursor position pixel by pixel and it provides a reliable left-click operation. However, the results of the EMGEGT system was evaluated inside a laboratory environment, further experiments need to be conducted with individuals with motor difficulties [28].

Hornof and Cavender (2005) introduced 'EyeDraw' software program. This program, when run on a computer, with an eye tracking device enables individuals with severe motor impairments to draw with their eyes. This method has been tested successfully on children and young adults with and/or without disabilities. However, the program might be difficult to use at first. If young learners have a constant caregiver's attention at the beginning EyeDraw gets easier with practice. EyeDraw Version 1 was extended to Version 2 according to the students' observations and feedback [29].

\section{LEARNING DIFFICULTIES}

\section{A. Learners with Autistic Spectrum Disorders}

One category within the group of 'Developmental Disorders' is known as Autistic Spectrum Disorders (ASD). ASD is a set of developmental problems that affect the social and communication skills. According to the diagnostic systems of World Health Organisation and American Psychiatric Association the umbrella of ASD includes a number of conditions e.g. autism; Asperger's syndrome; Rett's syndrome; semantic pragmatic disorder; atypical autism; pervasive developmental disorder-not otherwise specified; childhood disintegrative disorder [12], [30]. Today as a result of research the use of ICTs has gathered accumulative evidence around it. The diagnosis of autism or the rest of the ASD is in most of the times a result of the several traditional assessment tests that are available to professionals. However, the latest years, important attempts have been made in the field of ICT assessment. In addition, a large number of studies have employed ICT to facilitate and train youngsters and adults with Autistic Spectrum Disorders (ASD).

Ozonoff et al., (2004) developed the Cambridge Neuropsychological Test Automated Battery (CANTAB), a computer-administered set of neuropsychological tests designed to examine specific components of cognition. These tests examine the integrity of frontal functions since several studies support involvement of frontal cortex in autism. This method was tested to 79 participants with autism and 70 typical controls and the results indicated that the autism group had difficulties in planning efficiency and extradimensional shifting relative to controls comparing to the control group. Based on the results of this study, they argued that there is frontal lobe involvement in autism [31].

Vera et al., (2007) presented the use of 'Real Time' graphic applications as intervention tools in the educational process for people with learning difficulties. Their main features are the use of 3D graphics, the user only needs a computer (with screen, keyboard, mouse and joystic) and he/she can interact with the tool easily. They can be used from people who have specific problems in attention, perception, memory, people with down syndrome and autism. These 'Real Time' applications give the users the chance to understand and control abstract concepts, very difficult to represent in real world [32].

Tseng and Yi-Luen Do (2010) presented a novel design prototype ICT application for children with ASD. The Facial Expression Wonderland (FEW) application is designed to improve the ability of ASD learners in facial expression recognition. FEW is a daily training tool which consists of different levels. Moreover, requires learners with ASD to play in a everyday basis in order to improve their skills in facial expression recognition and 'Theory of Mind' (the ability to understand mental status of other people). The real impact of FEW application is not yet evaluated and is to be estimated in the future [33].

In the same year Tanaka et al., (2010) designed a computer-based intervention relevant to the above the 'Let's Face It!' program. It consists of seven interactive computer games which aim at the specific face impairments associated with the condition of autism. This method has been tested on children diagnosed with ASD who received a twenty hours of training with the program. It is an intervention method which can be easily implemented in home and /or school setting without direct supervision with encouraging results [34].

\section{B. Learners with Reading and Writing Difficulties}

Proficient reading and writing is one of the major tasks a young learner will achieve in his or her lifetime. It is a process that depends upon a wide range of component skills and needs several years to master fully. A large number of researches support that pre-reader's knowledge of the alphabet is an important predictor of later reading success [35], [36]. This why an early identification of these difficulties is of major importance in order to use later the appropriate intervention methods that will help the child overcome his or her difficulties. Accumulative research has also focused on several software applications concerning the intervention of the various reading and writing difficulties.

One of the most widely used software tools is the Cognitive Profiling System (CoPS), a computerized psychometric assessment system which identifies the cognitive strengths and difficulties for ages 4-8. CoPS consists of eight tests in the form of games and a total assessment time of no longer than twenty minutes. The students are tested in sequential and associative memory, auditory and color discrimination and phonological awareness. CoPS is used across the UK, Scotland and British schools around the world [8], [37].

Lange et al., (2009) presented the effects of using an assistive software homophone tool on students with reading difficulties who were at least one year behind in reading. The homophone tool is used to point errors in learners' own writing. The pupils who participate in the research used Microsoft Word on a Windows-based laptop PC as the platform for accessing proofreading passages. Three groups were used to evaluate the effect of homophone tool by reading the passages under three conditions; with the homophone tool, with homophones highlighted only, or with no help. The different results amongst the three groups indicated that highlighting 
improve students' performance (14.6\% improvement from no help) and offering homophonic choices could lead to additional benefits [38].

Starcic et al., in 2010 present the findings of the use of SEVERI, an e-learning environment for students who have difficulties with reading, writing and perceiving. It includes tools such as guidance messages, a learning diary, calendar, library, tasks, materials and group-specific discussions. The SEVERI project was adapted to the education context of five countries. This research supports the fact that SEVERI provides students guidance in their learning when at the same time helps teachers to improve the planning and organization of their teaching. In addition it supports networking and co-operation between specialists and parents [39].

\section{Dyslexic Learners}

One of the most common and most studied types of Developmental Disorders is the difficulty in reading as well as in spelling and writing, known as dyslexia. The Code of Practice highlights the importance of an evidence-based diagnosis and provides also the framework for all the professionals to examine and identify students' needs through the use of assessment tools [4]. Recently, the use of technology provides school staff the opportunity to engage in identifying and in overcoming dyslexia with saving in time and labour.

Lucid Adult Development Screening (Lads) was introduced by Singleton et al., in 2002. Lads is developed to screen for dyslexia from age sixteen and older in different settings (e.g. schools, colleges). Areas such as speeded lexical access, memory, phonological coding are examined in an approximately twenty minutes short test. It is a self-administered test and it is currently used in over one thousand establishments [40], [41].

Gregor et al., (2003) developed 'Seeword', a word processing environment which assist dyslexic computer users when producing and reading text. The initial prototype was designed in Microsoft Wordtm version 7 in 'word basic', the built in macro lan guage. The program has been tested on dyslexic school students aged 14-16 years and the experimental results have indicated that they were able to read standard texts from a screen more accurately by using 'Seeword' [42].

\section{Learners with Difficulties in Mathematics}

Even though the mathematical level of students with special needs is generally with standardized written tests, amongst the latest years significant attempts have been made for an ICT assessment of difficulties in mathematics [43]. Difficulties in mathematics affect also children with or without special needs. This is why several sets of teaching and training tools were designed to enhance pupils' learning experience.

Hung and Su (2010) have implemented a software package which consists of a computerized dynamic assessment model (MCAT) and a two-phase ICT infused intervention. The aim of this approach is to investigate the predictive validity of the goal orientation change for mathematics slow learners. The MCAT system was designed in order to collect data of computer-based assessment on spatial and numerical working memory (CANSWM-R), a simplified version of CANSWM. The study showed that the identification of goal orientation change is a useful predictor for ICT infused mathematics intervention impact [44].

In 2006 Wilson et al., developed an adaptive computer game for intervention of dyscalculia, 'The Number Race'. This software aims at training children on an entertaining numeral comparison task by introducing problems adapted to the performance level of every individual. According to the authors' study this method was tested by using mathematical simulation and by a group of students with difficulties in mathematics. The results indicated that this software application could be effective in the remediation of dyscalculia, at least for children aged $7-8$ and under [45], [46].

\section{E. Learners with Difficulties in Memory}

Memory consists of abilities such as receiving and processing of received information, creation of a permanent record of the encoded information and calling back the stored information. Memory skills of children with special needs have been a domain of great research for professionals over the latest years. There is evidence that shows that poor memory skills characterize children failing to progress normally in different areas of needs [47], [48].

Alloway in 2007 presented the 'Automated Working Memory Assessment' (AWMA), a standarised computerized tool. This tool enables teachers and psychologists to assess working memory skills with a user-friendly interface. AWMA includes three levels of assessment. AWMA Screener is designed for students with suspected working memory difficulties, AWMA: Short Form (AWMA-S) is used for screening learners who are suspected to have memory deficits, but the specific area of their difficulties is not known and AWMA: Long Form (AWMA-L) is suitable for confirmation of working memory problems for learners identified as having working memory problems in the classroom. The results of AWMA's use suggest that working memory skills in individuals with memory deficits are relatively stable over the course of the school year. There was also a high degree of concurrence in performance between the AWMA and the WISC-IV Working Memory Index [49].

Van der Molen et al., (2010) created the 'Odd Yellow' training, a computer-based working memory tool to train adolescents with mild to borderline intellectual disabilities. In the 'Odd Yellow' method a sequence of three similar looking images is shown on the computer screen. One of the three figures is slightly different called the 'odd-one-out' while the other two are identical. They are all drawn in black apart from one of the two identical shapes, which is yellow. The user has to recreate the location of the odd-one-out and the location of the yellow figure shape. Experimental results showed improvement of students' working memory on several outcome measures [50].

\section{F. Attention Deficit Hyperactivity Disorder (ADHD) and Attention Deficit Disorder (ADD) Learners}

Learners with ADHD or ADD are usually characterized by a set of behaviour problems (abnormal levels of inattention, hyperactivity or their combination) that are remarkably stable over time. Research in the field of diagnosis and intervention has improved the ways and the various instruments that are now used. 
Bolfer et al., (2010) attempted to examine the reaction time in a computer-based assessment test in individuals with ADHD and normal controls using a visual voluntary attention psychophysical test (VVAPT). This method was tested on boys aged 9-12 with ADHD diagnosis according to DSM-IV, without comorbities, IQ $\geq 89$ and never treated with methylphenidate. The control group followed the same criteria for gender, age and IQ. The results showed that the ADHD group indicated reaction time higher than normal controls and a graduated loss of sustained attention [52].

Chatzara et al., (2010) developed an intelligent emotional agent for pupils with ADD in order to improve the communication channel between the user and the machine for e-learning systems. The proposed agent, Sophia who imitates face to face communication, reacts to events that are taking place in the environment and the latest changes accordingly to agent's behavior. The agent receives events through a perception module while a decision module is responsible to decide what behavior the agent must have. This e-learning platform can be used by several users that have to provide a few personal details in order to use the system. This method was tested on 52 students from higher education and the results indicated that Sophia managed to attract students' attention in a suitable with learning manner [53].

\section{CONCLUSIONS}

The scope of this study, given the multitude of manifestations of special educational needs was to examine the most representative studies over the last decade which exploiting ICT, contribute to independent pupil learning and curriculum. The use of ICT has also played a major part in shaping the knowledge and skills of school staff, therapists, special educators etc. Diagnostic tools provide them with the possibility to employ different ICT strategies which might lead to an easier understanding of children's learning differences. In addition, ICT intervention tools support activities of life of these students such as learning, leisure and work. In general, several benefits are limited cost, greater precision and savings in time and labour. However, there are also several fields that require further research such as investigations into the reliability and validity of the diagnostic ICT tools, adaptations of diagnostic and intervention tools to the various needs of students of different settings and development of ICT programs for the rest of the special educational needs. The results of the current study are encouraging and there is a general consensus that ICTs do play a significant role in both ensuring and enhancing learning and life skills programs of students with special educational needs.

\section{REFERENCES}

[1] Dillon, P.: Trajectories and tensions in the theory of information and communication technology in education. British Journal of Educational Studies, 52 (2), pp. 138-150, (2004). http://dx.doi.org/10.1111/j.1467-8527.2004.00259.x

[2] Stevens, C.: 'Information and communication technology, special educational needs and schools: a historical perspective of UK government initiatives', in Florian, L., Hegarty, J. (Eds), ICT and Special Educational Needs: a Tool for Inclusion, Open University Press, Buckingham, 21-34, (2004).

[3] Meijer, C., Soriano, V., Watkins,A : Inclusive Education across Europe: Reflections upon 10 Years of Work from the European Agency for Development in Special Needs Education Childhood Education, 83(6), p361, (2007).
[4] Department for Education and Skills, Special Educational Needs Code of Practice. London: DfES, (2001).

[5] Brodin, J. (2010).Can ICT give children with disabilities equal opportunities in school? Improving Schools, 13(1),pp. 99-112. http://dx.doi.org/10.1177/1365480209353483

[6] Edyburn, D.L.: Scholarly endeavors: Conducting a comprehensive review of the literature using digital resources. Journal of Special Education Technology, 16(1),pp. 49-52, (2001).

[7] Williams, P., Jamali H.R., Nicholas, D. : Using ICT with people with special education needs: what the literature tell us. Aslib Proceedings, 58(4), $330-345$, (2006). http://dx.doi.org/10.1108/ 00012530610687704

[8] Singleton, C.: Using computer-based assessment to identify learning problems, in Florian, L., Hegarty, J. (Eds), ICT and Special Educational Needs: a Tool for Inclusion. Open University Press, Buckingham, pp. 46-63, (2004).

[9] Bottge, B.A., E. Rueda, J.M. Kwon, T. Grant, and P. LaRoque. : Assessing and tracking students: problem solving performances in anchored learning environments. Educational Technology Research and Development 57(4), 529-52, (2009). http://dx.doi.org/10.1007/s11423-007-9069-y

[10] Mooij, T.: 'Design of educational and ICT conditions to integrate differences in learning: Contextual learning theory and a first transformation step in early education', Computers in Human Behavior 23(3), 1499-1530, (2007). http://dx.doi.org/10.1016/i.chb. 2005.07 .004

[11] Adam, T., Tatnall, A., Using ICT to Improve the Education of Students with Learning Disabilities. In: Kendall, M., Samways, B. (eds) Learning to Live in the Knowledge Society, 63-70. Springer, New York, (2008).

[12] World Health Organization. The International Classification of Diseases, 10th Revision (ICD-10) Classification of Mental and Behavioral Disorders: Diagnostic Criteria for Research. Geneva, Switzerland: World Health Organization; 1993

[13] Douglas, G., Long, R.: An observation of adults with visual impairments carrying out copy-typing tasks. Behaviour \& IT , 22(3),pp.141-153, (2003).

[14] Sales, A.S., Evans, S., Musgrove, N., and Homfray, R., (in press), 'Full-screen magnification on a budget: Using a hardware-based multi-display graphics card as a screen-magnifier,' British Journal of Visual Impairment, 24,(3),pp. 135-140, (2006). http://dx.doi.org/10.1177/0264619606066188

[15] Fujiyoshi, M., Fujiyoshi, A., and Aomatsu, T.: New Testing Method for the Dyslexic and the Newly Blind with a Digital Audio Player and Document Structure Diagrams. Computers Helping People with Special Needs Lecture Notes in Computer Science, 6179,pp. 116-123, (2010).

[16] Westin, T.: Game accessibility case study: Terraformers a realtime 3D graphic game. In Proc. of the $5^{\text {th }}$ International Conference on Disability, Virtual Reality and Associated Technologies, pp. 95-100, (2004).

[17] Raisamo, R.,Hippula, A., Patomaki, S., Tuominen, E., Pasto, V., Hasu, M.: Testing Usability of Multimodal Applications with Visually Impaired Children," IEEE Multimedia, 13, (3), pp. 70-76, (2006). http://dx.doi.org/10.1109/MMUL.2006.68

[18] Choi, S.H. and Walker, B.N.: Digitizer Auditory Graph: Making Graphs Accessible to the Visually Impaired. Proceedings of the 28th of the international conference extended abstracts on Human factors in computing systems, pp.3445-3450, (2010).

[19] Margolis, R.H., Glasberg, B.R., Creeke : AMTAS: Automated method for testing auditory sensitivity: Validation studies. International Journal of Audiology, 49(3), pp.185-194.(2010). http://dx.doi.org/10.3109/14992020903092608

[20] Ho, A.T.P., Hildreth, A.J. and Lindsey, L.: Computer-assissted autdiometry versus manual audiometry. Otol Neurol, 20(7), pp.876-883, (2009). http://dx.doi.org/10.1097/MAO.0b013e318 $\underline{1 \mathrm{~b} 120 \mathrm{~d} 0}$

[21] Swanepoel, de W., Koekemoer, D. and Clark, J.: Intercontinental hearing assessment- A study in tele-audiology, Journal of Telemedicine and Telecare,16(5),pp.248-252(2010). http://dx.doi.org/ $10.1258 /$ itt.2010.090906

[22] Swanepoel, de W., Olusanya, B.O. and Mars, M.: Hearing healthcare delivery in sub-Saharan Africa-A role for tele-audiolody. 
Journal of Telemedicine and Telecare,16(2),pp.53-56(2010). http://dx.doi.org/10.1258/jtt.2009.009003

[23] Drigas, A.S., Kouremenos, D., Kouremenos, S. and Vrettaros, J. An e-Learning System for the deaf people. Information Technology Based Higher Education and Training, ITHET $6^{\text {th }}$ Annual International Conference, 2005.

[24] Miller, J. D., Watson, C. S., Kistler, D. J., Preminger, J. E., Wark, D. J.: Training listeners to identify the sounds of speech: II. Using SPATS software. Hearing Journal, 61(10), pp. 29-33, (2008)

[25] Drigas, A.S., Kouremenos, D., Vrettaros, J. Teaching of English to Hearing Impaired Individuals Whose Mother Language is the Sigh Language. In : M.D. Lytras et al. (Eds), pp.263-270, 2008.

[26] Chen, M.C., Chu, C.N., Wu,T.F. and Yeh, C.C., Computerized Assessment Approach for Evaluating Computer Interaction Performance, In Proceedings of ICCHP'2006, pp.450-456, (2006).

[27] Chen, M.C., Lin, Y.L. and Ko, C.C.: Computerized Assessing the Mouse Proficiency through Multiple Indicators, In Proceedings of ICCHP'2010, pp. 193-199, (2010).

[28] Chin, C.A., Barreto, A., Cremades, J.D. and Adjouadi, M.: Integrated electromyogram and eye-gaze tracking cursor control system for computer users with motor disabilities. Journal of Rehabilitation \& Development, 45(1), pp. 161-174, (2008). http://dx.doi.org/10.1682/JRRD.2007.03.0050

[29] Hornof, A. and Cavender, A.: EyeDraw: enabling children with severe motor impairments to draw with their eyes. CHI '05 Proceedings of the SIGCHI conference on Human factors in computing systems, pp. 161-170, (2005).

[30] American Psychiatric Association: Diagnostic and Statistical Manual of Mental Disorders, $4^{\text {th }}$ edition. (DSM-IV). Washington, DC: American Psychiatric Association, (1994).

[31] Ozonoff, S., Cook, I., Coon, H., Dawson, G., Joseph, R.M., Klin, A., McMahon, W.M., Minshew, N., Munson, J.A., Pennington, B.F., Rogers, S.J., Spence, M.A., Tager-Flusberg, H., Volkmar,F.R. and Wrathall, D.: Performance on Cambridge Neuropsychological Test Automated Battery Subtests Sensitive to Frontal Lobe Function in People with Autistic Disorder: Evidence from the Collaborative Programs of Excellence. Journal of Autism and Developmental Disorders, 34(2),pp..139-150, (2004). http://dx.doi.org/10.1023/B:JADD.0000022605.81989.cc

[32] Vera, L., Campos, R., Herrera, G. and Romero C. Computer graphics applications in the education process of people with learning difficulties. Computer and Graphics,31, pp.649658,(2007). http://dx.doi.org/10.1016/j.cag.2007.03.003

[33] Tseng, R., Yi-Luen and Do, E.: Facial Expression Wonderland (FEW) - A Novel Desing Prototype of Information and Computer Technology (ICT) for Children with Autism Spectrum Disorder (ASD). $1^{\text {st }}$ ACM IHI Symposium, Virginia, USA, 2010.

[34] Tanaka J.W., Wolf J.M., Klaiman C., Koenig K., Cockburn J., Herlihy L., Brown C., Stahl S., Kaiser M.D., Schultz R.T.: Using computerized games to teach face recognition skills to children with autism spectrum disorder: the Let's Face It! program. The Journal of Child Psychology and Psychiatry, 51(8),pp. 944-95, (2010). http://dx.doi.org/10.1111/j.1469-7610.2010.02258.x

[35] Macmillan, B. M.: Rhyme and reading: A critical review of the research methodology. Journal of Research in Reading, 25 (1), 442, (2002). http://dx.doi.org/10.1111/1467-9817.00156

[36] Roberts, L. and McDougall, S.: Explaining Performance in the Orthographic Analogy Task: Phonological Priming, Phonological Skills and Letter-sound Knowledge. Journal of Experimental Child Psychology, 84 (4), pp. 310-337, (2003).

[37] Singleton, C. H., Thomas, K. V., \& Leedale, R. C.: CoPS 1 cognitive profiling system manual (2nd ed.). Beverley, East Yorkshire, UK: Lucid Research Ltd., (2001).

[38] Lange, A. A., Mulhern, J. and Wylie, J. Proofreading Using an Assistive Software Homophone Tool: Compensatory and Remedial Effects on the Literacy Skills of Students With Reading Difficulties, Journal of Learning Disabilities, 24(4), pp. 322-335, (2009). http://dx.doi.org/10.1177/0022219408331035

[39] Starcic, A.I., Niskala and M. Colloquium: Vocational students with severe learning difficulties learning on the Internet. British Journal of Educational Technology,41, (6), pp. 155-159, (2010). http://dx.doi.org/10.1111/j.1467-8535.2010.01128.x
[40] Singleton, C. H., Horne, J., Thomas, K. V., \& Leedale, R. C.: LADS version 1.0 administrator's manual. Beverley, East Yorkshire, UK: Lucid Innovations Ltd., (2002).

[41] Singleton, C. and Horne, J. Computerised screening for dyslexia in adults, Journal of Research in Reading, volume 32 (1),pp. 137152. (2009). http://dx.doi.org/10.1111/j.1467-9817.2008.01386.x

[42] Gregor, P., Dickinson, A., Macaffer, A. and Andreasen, P.: SeeWord - a personal word processing environment for dyslexic computer users. British Journal of Educational Technology, 34(3), pp. 341-355, (2003). http://dx.doi.org/10.1111/1467-8535.00331

[43] Peltenburg, M., Heuvel-Panhuizen, M. and Robitzsch, A.: ICTbased dynamic assessment to reveal special education students' potential in mathematics. Research Papers in Education, 25(3), pp. 319-334, (2010). http://dx.doi.org/10.1080/02671522.2010.498148

[44] Hung, P.I. and Su, I.H.: Applying Affective Assessment to Detect the ICT Infused Mathematics Intervention Effect, 2nd International Asia Conference on Informatics in Control, Automation and Robotics, pp. 321-323, (2010).

[45] Wilson, A.J., Dehaene, S., Pinel1, P., Revkin, S.K., Cohenand L. and Cohen, D.: Principles underlying the design of "The Number Race", an adaptive computer game for remediation of dyscalculia, Behavioral and Brain Functions , 2(19), (2006).

[46] Wilson AJ, Revkin SK, Cohen D, Cohen L, Dehaene S: An open trial assessment of "The Number Race", an adaptive computer game for remediation of dyscalculia, Behavioral and Brain Functions, 2(20), (2006).

[47] Gathercole, S. E., Pickering, S. J., Knight, C., \& Stegmann, Z.: Working memory skills and educational attainment: Evidence from national curriculum assessments at7 and 14 years of age. Applied Cognitive Psychology, 18, pp. 1-16, (2004). http://dx.doi.org/10.1002/acp.934

[48] Bull, R., \& Scerif, G.: Executive functioning as a predictor of children's mathematics ability: Inhibition, task switching, and working memory. Developmental Neuropsychology, 19, 273-293, (2001). http://dx.doi.org/10.1207/S15326942DN1903 3

[49] Alloway, T. P., Gathercole, S. E., Kirkwood, H. and Elliot, J.: The working memory rating scale: A classroom-based behavioral assessment of working memory, Learning and Individual Difference, 19(2), June 2009, pp. 242-245. http://dx.doi.org/10.1016/ j.lindif.2008.10.003

[50] Van der Molen, M.J., Van Lult, J.E.H., Van der Molen, M.W., Klugkist, I. and Jongmans, M.J., Effectiveness of a computerized working memory training in adolescents with mild to borderline intellectual disabilities, Journal of Intellectual Disability Research, 54(5), pp.433-447, (2010). $\quad$ http://dx.doi.org/10.1111/j.13652788.2010.01285.x

[51] Parsons, T.D., Bowerly,T., Buckwalter, J.G. and Rizzo, A.A., Controlled Clinical Comparison of Attention Performance in Children with ADHD in a Virtual Reality Classroom Compared to Standard Neuropsychological Methods, Child Neuropsychology, 13(4), pp.363-381, (2007). $\quad \underline{\text { http://dx.doi.org/10.1080/13825 }}$ $\underline{580600943473}$

[52] Bolfer, C., Casella, E.B., Baldo, M.V.C., Mota, A.M, Tsunemi, M.H., Pachero, S.P. and Reed, U.C.: Reaction time assessment in children with ADHD, Arquivos de Neuro-Psiquiatria, 68(2), pp. 282-286, (2010). http://dx.doi.org/10.1590/S0004-282X201000 $\underline{0200025}$

[53] Chatzara, K., Karagiannidis, C., Stamatis, D.: An Intelligent Emotional Agent for Students with Attention Deficit Disorder, International Conference on Intelligent Networking and Collaborative Systems (INCOS), pp.252-258, (2010). http://dx.doi.org/ $\underline{10.1109 / \text { INCOS.2010.98 }}$

\section{AUTHORS}

Athanasios Drigas is a Senior Researcher at N.C.S.R. Demokritos. He is the Coordinator of Telecoms Lab and founder of Net Media Lab since 1996. From 1985 to 1999 he was the Operational manager of the Greek Academic network. He has been the Coordinator of Several International Projects, in the fields of ICTs, and e-services (elearning, e-psychology, e-government, e-inclusion, eculture etc). He has published more than 200 articles, 7 
PAPER

SPECIAL EDUCATION AND ICTS

books, 25 educational CD-ROMs and several patents. He has been a member of several International committees for the design and coordination of Network and ICT activities and of international conferences and journals. (e-mail: dr@iit.demokritos.gr).

Elena Rodi Ioannidou (MA in Special Educational Needs) is a Special Education Teaching Professional. She has participated in various research projects regarding the use of Information and Communication Technologies
(ICTs) in Special Education. She is also with NCSR DEMOKRITOS, Institute of Informatics and Telecommunications, Net Media Lab, Athens, Greece. (e-mail: elena.ioan@hotmail.com).

This article is an extended and modified version of a paper presented at the International Conference on Interactive Collaborative Learning (ICL2012), held 26 - 28 September 2012, in Villach, Austria. Received 11 February 2013. Published as resubmitted by the authors 25 April 2013. 